\title{
Sistem Rekomendasi Penjualan Alat Musik Modern Menggunakan Metode Simple Additive Weighting
}

\author{
Yani Sugiyani $^{1}$, Adji Rizkiyanto ${ }^{2}$ \\ ${ }^{12}$ Program Studi Informasi, Fakultas Teknologi Informasi- Universitas Serang Raya \\ Jl. Raya Cilegon - Serang Km.5 Taman Drangong Kota serang - Banten, indonesia \\ yani.sugiyani@yahoo.co.id \\ 2adjirizky232@yahoo.co.id
}

\begin{abstract}
Alat musik adalah suatu alat instrument yang dibuat dan dimodifikasikan untuk suara yang berirama. alat musik berbagai macam jenis, dan jika ingin melakukan pembelian terkadang kita bingung untuk menyesuaikan kriteria produknya. Keberhasilan suatu perusahaan dagang dalam melaksanakan misinya tidak terlepas dari peran strateginya, ragam dan jumlah barang jasa yang dipasok bergantung pada jenisnya. Perusahaan dagang yang memiliki barang yang modern dengan harga terjangkau pastinya akan terbantu untuk sistem penjualan, lalu dengan sistem promosi di dunia maya dan ditampilkan sistem rekomendasi konsumen pastinya perusahaa akan terus meningkat penjualannya. Dalam suatu perusahaan dagang perlu adanya sistem pendukung keputusan, karena untuk memberikan alternatif dalam pengembangan penjualan, dan juga perlunya rancangan rekomendasi konsumen untuk membantu ide-ide dari konsumen yang berupa website.

Sistem ini dikembangkan menggunakan perancangan aplikasi $E$ commerce melalui program Hypertext Processor sebagai bahasa pemogramannya, dan MysQL sebagai database. Dalam hal ini penulis menggunakan metode Simple Additeve Weigthing (SAW), metode ini dipilih karena memiliki cara-cara untuk meperbandingkan nilai bobot pada kriteria barang. sehingga keputusan yang diambil dapat lebih obyektif. Metode SAW adalah penjumlaha terbobot dengan konsep dasar mencari penjumlahan terbobot dari rating kinerja pada setiap alternatif pada semua atribut.
\end{abstract}

Kata kunci: alat musik, sistem pendukung keputusan, e-commerce, simple additive weighting.

\section{LATAR BELAKANG}

Alat musik adalah sebuah alat jika digunakan terdengar suara yang berirama dengan sesuai permintaan pengguna maupun pendengar. Berbagai alat musik bermacam-macam jenis, dan jika ingin melakukan pembelian terkadang kita bingung untuk menyesuaikan kriteria produknya. Keberhasilan suatu perusahaan dagang dalam melaksanakan misinya tidak terlepas dari peran strateginya, ragam dan jumlah barang jasa yang dipasok bergantung pada jenisnya. Perusahaan dagang yang memiliki barang yang modern dengan harga terjangkau pastinya akan terbantu sistem penjualan, lalu dengan sistem promosi di dunia maya dan ditampilkan sistem rekomendasi konsumen pastinya perusahaa akan bertambah meningkat untuk penjualannya.
Dalam suatu perusahaan dagang perlu adanya sistem pendukung keputusan, karena untuk memberikan alternatif dalam pengembangan penjualan, dan juga perlunya rancangan rekomendasi konsumen untuk membantu ide-ide dari konsumen yang berupa website.

Berdasarkan permasalahan tersebut maka dibuatkan perancangan sistem yang berupa aplikasi, sistem ini dikembangkan menggunakan perancangan aplikasi Ecommerce melalui program Hypertext Processor sebagai bahasa pemogramannya, dan MysQL sebagai database. Dalam penelitian ini digunakan metode Simple Additeve Weigthing (SAW), metode ini dipilih karena memiliki cara untuk meperbandingkan nilai bobot pada kriteria barang. sehingga keputusan yang diambil dapat lebih obyektif. Metode SAW adalah penjumlaha terbobot dengan konsep mencari penjumlahan terbobot dari rating kinerja pada setiap alternatif pada semua atribut

Dari alur sistem ecommerce disertai dengan rekomendasi, maka konsumen atau pengunjung dapat melakukan permintaan barang, adapun tampilan tersebut sudah disediakan di menu rekomendasi berupa kriteria, dari hasil rekomendasi yang dilakukan konsumen, sistem akan menampilkan berupa saran dan informasi tersebut hanya ada dalam database sistem saja, untuk menambah database untuk rekomendasi, admin tinggal mengolala data saja,dari mulai kedetailan produk sampe banyaknya produk. Semakin banyak pengelolaan produk, semakin luas juga infoormasi yang didapatkan oleh konsumen.

Dengan demikian aplikasi ecommerce rekomendasi inni, mampu meningkatkan kepuasan pelanggan dan perusaan toko pun akan berkembang

\section{DASAR TEORI}

\section{A. Simple Additive Weighting (SAW)}

(Munandar Ai. Tb : 2013). Simple Additeve Weighting method sering disebut dengan istilah metode penjumlahan terbobot. Konsep dasarnya adalah mencari penjumlahan terbobot dari rating kinerja pada setiap alternatif pada semua atribut. Metode ini membutuhkan proses normalisasi matriks 
keputusan (X) ke suatu skala yang dapat diperbandingkan dengan semua rating alternatif yang ada.

Formula untuk melakukan normalisasi tersebut adalah sebagai berikut:

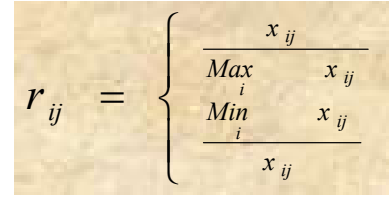

jika $\mathrm{j}$ adalah atribut biaya (cost) Dengan rij adalah rating kerja ternormalisasi dari alternatif $\mathrm{Ai}$ pada atribut $\mathrm{Cj} ; \mathrm{i}=1,2$, $3 \ldots \mathrm{m}$; dan $\mathrm{j}=1,2,3 \ldots \mathrm{n}$ Nilai preferensi untuk setiap alternatif (Vi) diberikan sebagai:

$$
V_{i}=\sum_{j=1}^{n} w_{j} r_{i j}
$$

Nilai Vi yang lebih besar mengindikasikan bahwa alternatif Ai lebih terpilih dengan demikian, dapat dikatakan bahwa masalah MADM adalah mengevaluasi $\mathrm{m}$ alternatif $\mathrm{Ai}\{\mathrm{i}=1$, $2, \ldots, \mathrm{m}\}$ terhadap sekumpulan atrbut atau kriteria $\mathrm{Cj}\{\mathrm{j}=1$, $2, \ldots, n\}$ dimana setiap atribut saling tidak bergantung satu dengan yang lainnya. Matriks keputusan alternatif terhadap setiap atribut $X$.

\section{ANALISIS DAN PERANCANGAN SISTEM}

Permasalahan pada toko Unity Musik adalah berupa peningkatan penjualan dan sistem pembeliannya belum terkonsep terkomputerisasi, Dari analisa yang di amati dalam pengelolaan eccomerce dan rekomendasi online maka dikembangkangkannya sebuah rekomendasi yang terkadang pengunjung atau konsumen ketika membuka halaman web eccomerce bingung untuk memilih produk yang diinginkan. Maka dari itu penulis membuat program dengan menggunakan aplikasi design untuk merancang design yaitu Macromedia Dreamweaver, setelah itu penulis melakukan perancangan sistem tertulis dengan menggunakan Unified Modeling Languege (UML) yang berfungsi untuk menggambarkan sistem pada alur program yang ditampilkan, agar si pembaca paham akan alur sistem gambaran program. Dari perancangan mulai dari implementasi program sampai ke perncangan UML, maka dibutuhkan sistem pendukung keputusan untuk menentukan pilihan kriteria pada rekomendasi yaitu dengan menggunakan metode Simple Additive Weigthing (SAW). Dari metode tersebut ditentukan dalam tiga 3 kriteria yaitu Jenis Barang, Tahun Buatan dan Berat Kilogram pada produk, dari ketiga kriteria itu dibutuhkan alternative kriteria yaitu merek barang. Setelah diperbandingkan berupa nilai-nilai berupa angka dan diperhitungkan dari nilai kriteria sampai alternatife kriteria.
Setelah itu dijumlahkan manakah nilai yang paling besar yang banyak di kunjungi oleh para pengunjung. Dari hasil perhitungan oleh penulis, maka nilai angka yang paling besar adalah alternative 4 (Drum).

\section{B. Perhitungan simple additive weighting}

Dalam perhitungan SAW setiap kategori memiliki nilai yaitu Jenis Barang, Tahun Buatam dan Berat kilogram produk. Maka dilakukan perhitungan rata-rata sebagai berikut ini:

Tabel 4.1 Tabel rating kecocokan dari setiap alternative pada setiap kriteria

\begin{tabular}{|c|c|c|}
\hline C & Kriteria & Bobot \\
\hline C1 & Harga Barang & 100 \\
\hline C2 & Tahun Buatan & 80 \\
\hline C3 & Berat kg & 70 \\
\hline
\end{tabular}

Berikut Niali angka disetiap kriteria

1) Sub Kreteria Harga

\begin{tabular}{|c|c|}
\hline & Nilai Bobot \\
\hline HG 1.000.000 & 60 \\
\hline HG1.000.000-5.000.000 & 70 \\
\hline HG5.000.000-10.000.000 & 80 \\
\hline HG10.000-15.000.000 & 90 \\
\hline
\end{tabular}

2) Sub kriteri Tahun Pembuatan

\begin{tabular}{|c|c|}
\hline Tahun & Nilai Bobot \\
\hline TH2000 & 50 \\
\hline TH2000-2005 & 60 \\
\hline TH2005-2010 & 70 \\
\hline TH2010-2014 & 80 \\
\hline
\end{tabular}

3) Subkriteria Berat Kilogram Produk

\begin{tabular}{|c|c|}
\hline Berat & Nilai Bobot \\
\hline BR10kg & 80 \\
\hline BR10kg-20kg & 90 \\
\hline BR20kg-30kg & 100 \\
\hline
\end{tabular}

\section{d. Alternatif Kriteria}

\begin{tabular}{|l|c|c|c|c|c|}
\hline \multirow{2}{*}{ K } & \multicolumn{5}{|c|}{ Alternatif } \\
\cline { 2 - 6 } & Alternatif 1 & Alternatif 2 & Alternatif 3 & Alternati 4 & Alternatif 5 \\
\hline C1 & 100 & 55 & 75 & 55 & 90 \\
\hline C2 & 75 & 85 & 60 & 75 & 75 \\
\hline C3 & 60 & 65 & 90 & 85 & 60 \\
\hline
\end{tabular}


Tabel 4.2. Rating Kecocokan Setiap Alternatif Pada

\begin{tabular}{|l|l|l|l|}
\hline \multirow{2}{*}{ Alternatif } & \multicolumn{3}{|c|}{ Kriteria } \\
\cline { 2 - 4 } & $\begin{array}{c}\text { (C1) } \\
(\text { MAX) }\end{array}$ & $\begin{array}{l}\text { (C2) } \\
\text { (MAX) }\end{array}$ & $\begin{array}{l}\text { (C3) } \\
\text { (MAX) }\end{array}$ \\
\hline A1 & 100 & 75 & 65 \\
\hline A2 & 75 & 75 & 75 \\
\hline A3 & 90 & 60 & 60 \\
\hline A4 & 55 & 55 & 85 \\
\hline A5 & 90 & 65 & 85 \\
\hline
\end{tabular}

\section{Langkah - Langkah Penyelesaian}

1. Vektor bobot: $\mathrm{W}=[100,80,70]$

2. Matrik Keputusan $X$ berdasarkan kriteria bobot

$$
\mathrm{X}=\left\{\begin{array}{lll}
100 & 75 & 65 \\
75 & 75 & 75 \\
90 & 60 & 60 \\
55 & 55 & 85 \\
90 & 65 & 85
\end{array}\right\}
$$

Normalisasi matriks $\mathrm{X}$ menggunakan persamaan 1

$$
R i j=\frac{\mathrm{X}_{\mathrm{ij}}}{\mathrm{Max} \mathrm{Xij}_{\mathrm{ij}}} \quad R i j=\frac{\mathrm{X}_{\mathrm{ij}}}{\mathrm{Min} \mathrm{Xij}_{\mathrm{ij}}}
$$

Altermative A1

$r 11=\frac{100}{\operatorname{Ma}(100,600,70,80)}=100 \quad r 21=\frac{75}{\operatorname{Mr}(100,600,70,80)}=75$

$r 12=\frac{75}{\operatorname{Ma}(80,60,80,90)}=83.3 \quad r 22=\frac{75}{M_{a r}(80,60,80,90)}=83.3$

$r 13=\frac{65}{\operatorname{Mar}(70,70,80,90)}=72.2 \quad r 23=\frac{75}{\operatorname{Mar}(70,70,80,90)}=83.3$
Alternative 3

Alternative4

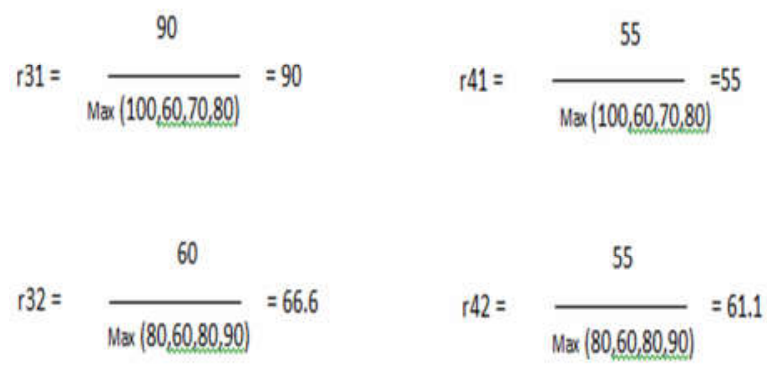

60
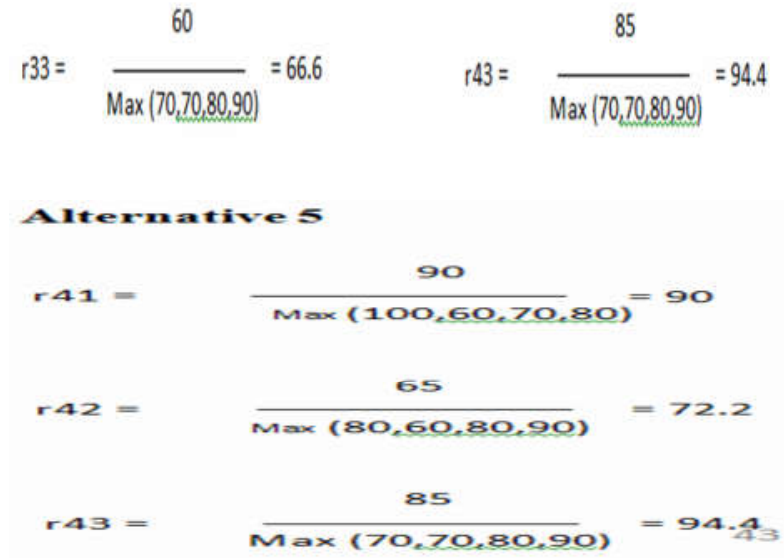

Dari hasil perhitungan di atas maka di dapat matriks ternomalisasi

$\mathrm{R}$ sebagai berikut

$$
\mathrm{R}=\left\{\begin{array}{lll}
100 & 83.3 & 72.2 \\
75 & 83.3 & 83.3 \\
90 & 66.6 & 66.6 \\
55 & 61.1 & 94.4 \\
90 & 72.2 & 94.4
\end{array}\right\}
$$

4. Mencari alternative terbaikmenggunakan persamaan 2

$$
\begin{aligned}
& V l=(100 \times 100)+(83.3 \times 80)+(72.2 \times 70)=21.718 \\
& V 2=(75 \times 100)+(83.3 \times 80)+(83 \times 70)=19.974 \\
& V 3=(90 \times 100)+(66.6 \times 80)+(66.6 \times 70)=18.990 \\
& V 3=(55 \times 100)+(61.1 \times 80)+(94.4 \times 70)=16.996 \\
& V 3=(90 \times 100)+(72.2 \times 80)+(94.4 \times 70)=21.384
\end{aligned}
$$


Dari hasil perhitungan perbandingan pada nilai bobot disetiap kriteria adalah V1 yang merupakan peringkat pertama karena memiliki nilai yang lebih besar dari nilai lain, V1 merupakan nilai preferansi dari alternatif A1, sehingga A3 atau dalam sistem rekomendasi penjualan online ini adalah Katagori Drum

\section{HASIL DAN PEMBAHASAN}

Hasil yang dibahas adalah sistem rekonemendasi penjualan online dengan menggunakan metode SAW.

Gambar 1. merupakan tampilan halaman daftar lowongan yang akan digunakan oleh pihak SCC dalam menentukan lowongan yang akan menggunakan metode SAW dalam pencarian calon karyawan yang sesuai.

Dari halaman daftar lowongan pihak SCC menekan tautan perhitungan SAW. Setelah itu maka halaman daftar alumni beserta tingkat kecocokan terhadap lowongan tersebut akan ditampilkan seperti gambar 2 .

\section{Gambar 1. Konsumen Memilih Barang}

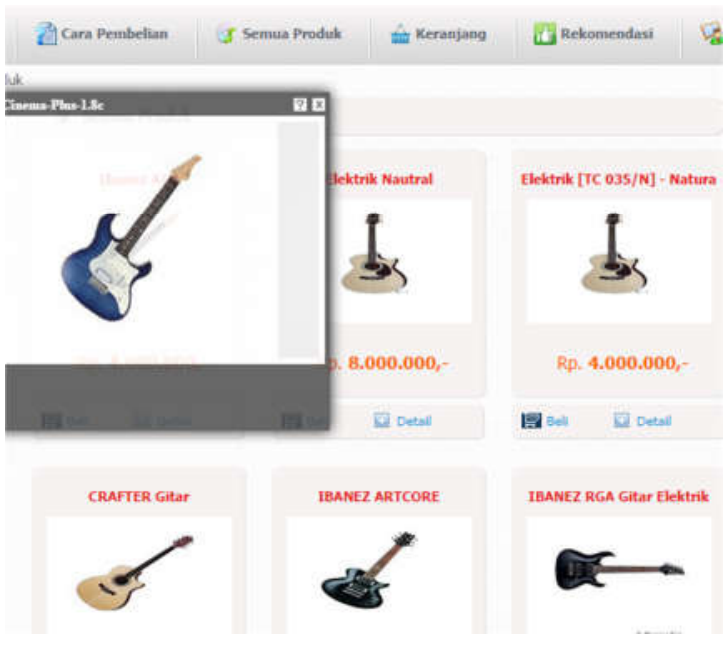

Gambar 2 Konsumen Melakukan Rekomendasi

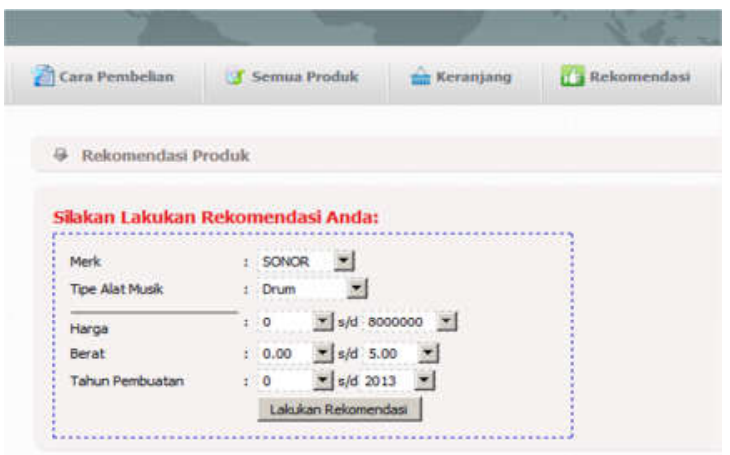

\section{KESIMPULAN}

Berdasarkan penelitian mengenai pembuatan aplikasi sistem rekomendasi penjulan online pada Toko Unity Musik, Maka dapat disimpulkan sebagai berikut:

A. Aplikasi ecommerce yang dibuat dapat memerikan kemudahan bagi pengunjung untuk melakukan pembelian, mulai dari memilih produk sampai menerima email notifikasi atas produk yang dibeli dan total biaya yang harus dibayar.

B. Aplikasi sistem rekomendasi ini mampu memberikan harapan pengunjung yang berupa saran, dalam pembelian produk .

C. Aplikasi ini memberikan sistem pendukung berupa media promosi yang lebih luas, sehingga yang nanti dapat meningkatkan penjulan pada Toko Unity Musik

\section{DAFTAR PUSTAKA}

[1] Ardina Ariani (2013). "Sistem Pendukung Keputusan Kelayan TKI Ke luar Negri Menggunakan FMADM". Ilmu Komputer (4) Hlm.336-343.

[2] Arianto (2012). "Sistem Pendukung Keputusan Pemilihan Karyawan Terbaik Dengan Metode SAW Studi Kasus Dipamela Swalayan”. Teknik Informatika (6) Hlm. 1-96.

[3] Noersasongko Edi (2014). "Sistem Pendukung Keputusan Kelayakan Pemberian Kredit Motor Menggunakan Metode Simple Additive Weigthing Pada Perusahaan Leasing HD Finance". Sistem Informasi Hlm 1-9.

[4] Nandang Hermanto (2012). "Sistem Pendukung Keputusan Menggunakan Metode Simple Additive Weigthing (SAW) Untuk Menentukan Jurusan Pada SMK BAKTI PURWOKERTO ”. Teknik Informatika (26) Hlm. 52-62.

[5] Hamdani (2013). "Sistem Pendukung Keputusan Pembelian Notbook Menggunakan Logika Fuzzy Tahani”.

[6] Mundandar Tb. Ai (2013). "Metode Penyelesian Masalah Pendukung Keputusan Menggunakan MADM". Sistem Informasi (26).

[7] Rachmadi (2013) "Sistem Pendukung Keputusan Penentuuan Proritas Pelanggan Dealer Suzuki SoekarnoHatta Malang Menggunakan Metode SAW dan AHP”. Ilmu Komputer.

[8] Sukenda (2011). "Sistem Pendukung Keputusan Untuk Memilih Kendaraan Bekas Dengan Menggunakan Metode Analitic Hierarchy Process (AHP)".Teknik Informatika (26).

[9] Rio Kiswandaru (2011). "Sistem Pendukung Keputusan Untuk Penerimaan Pegawai Baru Menggunakan Metode Simple Additive Weighting (SAW) Studi Kasus Rumah Sakit PKU Muhammadiyah Temanggung".Sistem Informasi (8) Hlm 6-12. 